\title{
Brincando com o espaço: uma proposta para as Escolas Técnicas de Saúde do SUS
}

\section{Playing with space: a proposal for SUS Technical Health Schools}

\author{
Luisa Regina Pessoa
}

Arquiteta, doutoranda em saúde pública na Escola Nacional de Saúde Pública

Av. Niemeyer, 925/Bloco A/ap. 1102

22450-221 Rio de Janeiro - RJ

luisa.pessoa@refus.rj.saude.gov.br

Este ensaio é o relato de uma experiência envolvendo a elaboração de projetos arquitetônicos para a construção de oito novas Escolas Técnicas de Saúde do Serviço Único de Saúde (ETSUS) e a reestruturação de sete escolas existentes. Para essa finalidade, o Projeto de Profissionalização de Trabalhadores da Área de Enfermagem (PROFAE) estruturou o Escritório de Projetos e Obras, vinculado ao Componente II do Projeto, composto por quatro arquitetos com experiência na área da arquitetura hospitalar e equipe técnica responsável pela modernização e fortalecimento das ETSUS e as escolas envolvidas no processo. Os trabalhos foram desenvolvidos de setembro de 2001 e outubro de 2002, quando foram concebidos os estudos preliminares das escolas e, posteriormente, os projetos executivos com vistas à licitação das obras. A concepção dos projetos arquitetônicos pautouse em algumas diretrizes básicas: concepção de espaços flexíveis que dessem conta de absorver a dinâmica das transformações da área da saúde, além de propiciar a capacitação de profissionais tanto em processos de trabalhos envolvendo tecnologias de alto custo como em atividades voltadas para a atenção básica em saúde; adoção de partidos arquitetônicos que visassem a racionalização de energia; a construção de uma identidade para as ETSUS; e concepção de projetos que facilitassem a sustentabilidade das escolas técnicas.

PALAVRAS-CHAVE: formação técnica em saúde, formação de recursos humanos, arquitetura em saúde, enfermagem, escolas técnicas de saúde.

The present article is a report of an experience in architectural projects for building eight new technical bealth schools for SUS (ETSUS) and remodeling seven existing schools. In order to do so, PROFAE (Project for the Training of Nursing Professionals) organized the Project and Building Bureau, related to Project Component II and composed by four architects specialized in hospital architecture. Besides, it engaged the technical staff in charge of remodeling and improving ETSUS and other participant schools. The project was developed from September 2001 and October 2002, when preliminary studies were carried out and the projects were concluded and submitted to legal approval. The development of the projects was based on the following principles: the creation of flexible spaces to cope with transformation in health services and with professional training both in bigh-cost technology and in activities related to basic bealth assistance, the choice of architectural emphasis on energy saving, the reinforcement of ETSUS identity and the creation of projects that would belp technical schools sustainability.

KEYWORDS: technical education in Health, education in buman resources, bealth architecture, nursing, technical bealth schools 
A experiência do setor da saúde era exclusiva com treinamento. Aí eu chegava dizendo que uma escola de formação de nível médio é uma grife e como tal ela precisa ter espaço para ir refazendo os seus registros, suas acumulações, e para todo mundo enxergar que aquele espaço é uma escola.

Izabel dos Santos (Castro, 2002, p. 62)

\section{Introdução}

Pode-se dizer que o Movimento Larga Escala, nasceu, no início da década de 1970, tendo se estruturado com base na experiência e disposição de duas incansáveis lideranças, Izabel dos Santos e Ena Galvão, e no acordo realizado entre o Ministério da Saúde, o Ministério da Educação e a Organização Pan-Americana de Saúde (OPAS), em 1975, concretizado no Programa de Preparação Estratégica de Pessoal de Saúde/PPRERS (Castro, 2002).

Consolidou-se, legalmente, em 1980, ${ }^{1}$ com a estruturação de escolas e centros formadores de pessoal de nível técnico nas secretarias estaduais de Saúde do Piauí, de Alagoas, de Rondônia, do Rio Grande do Norte, entre outros.

Somando-se a estas escolas pioneiras, ao longo da década de 1980, estruturam-se a da Bahia, do Rio de Janeiro, da Paraíba, do Espírito Santo, e de Montes Claros (MG), todos com sede própria, nos moldes do preconizado por Izabel.

Entre 1995 e 1996, consoantes com as diretrizes de Izabel de que "quem decide as prioridades das escolas é o serviço, o planejamento tem que ser conjunto" (Castro, 2002, p. 61), experimentou-se, no Centro de Formação de Pessoal de Nivel Médio do Rio Grande do Norte (CEFOPE/RN), um primeiro movimento nessa perspectiva de participação dos trabalhadores da saúde na construção da missão e metas dessa escola, cujos resultados podem ser observados no trabalho desenvolvido na atual sede própria do CEFOPE Manoel da Costa Souza, em Natal (RN).

Em 1999, o Ministério da Saúde criou o Projeto de Profissionalização dos Trabalhadores de Enfermagem (PROFAE), "com o objetivo de promover a melhoria da qualidade da atenção ambulatorial e hospitalar, por meio da redução do déficit de pessoal auxiliar de enfermagem qualificado e apoiar a dinamização e regulamentação do mercado de trabalho no setor saúde" (Sório, 2002, p. 21).

Entre as ações prioritárias do PROFAE está a modernização das 26 Escolas Técnicas de Saúde do Sistema Único de Saúde (ETSUS).

Paralelamente, em 1996, o Ministério da Saúde assinou um acordo de empréstimo com bancos internacionais - Banco Interamericano de

\footnotetext{
${ }^{1}$ Entrevista realizada com Ena Galvão em março de 2003.
} 
Desenvolvimento (BID) e Banco Mundial - , no valor de seiscentos e cinqüenta milhões de dólares mais contrapartida nacional de cem milhões de dólares, para readequação física e tecnológica da Rede SUS, da HEMORREDE e da Rede de Laboratórios Centrais de Saúde Pública, dando início ao Projeto de Reforço à Reorganização do SUS (REFORSUS).

Com recursos do REFORSUS, entre 1998 e 2003 foram adquiridos equipamentos médicos, de última geração, e de infra-estrutura de apoio técnico, como os de lavanderia, centrais de esterilização, centros de processamentos de dados e centrais de regulação, entre outros, imprimindo um tal grau de tecnologia na Rede SUS para o qual, certamente, não conta com recursos humanos de nível técnico suficientes em quantidade e qualidade para operá-los.

O estudo, ora apresentado, tem como objetivo repensar a concepção físico-funcional da Rede de Escolas Técnicas do SUS à luz desta nova realidade, desta nova Rede SUS que se configura, onde 1.200 estabelecimentos de saúde foram beneficiados com investimentos em reforma e aquisição de equipamentos sofisticados, com uma perspectiva de aumento de dez mil novos leitos, sendo 1.164 destinados às unidades de terapia intensiva para adultos, crianças e neonatos, além de outros tantos leitos, já existentes, totalmente reequipados (Brasil, 2002, p. 2).

\section{Premissas}

Entre as áreas da assistência priorizadas pelos investimentos do REFORSUS, destacam-se as de gestação de alto risco e de urgência e emergência que pressupõem a incorporação de tecnologias de alto custo, e grande complexidade, exigindo profissionais especialmente treinados para a manipulação de pacientes debilitados e altamente monitorados, como por exemplo numa UTI neonatal ou numa sala de grande emergência.

Por outro lado, os investimentos no Programa de Saúde da Família, em agentes comunitários e na atenção domiciliar, embora de menor complexidade tecnológica, requerem competências e habilidades diferenciadas das áreas anteriormente citadas, mas de igual modo importantes e específicas, necessitando, também, de uma intimidade com os procedimentos e rotinas, que antecedem à assistência real, uma vez que também lidam com uma clientela sensível e debilitada pela própria condição social em que se encontra.

Atualmente, as Escolas Técnicas de Saúde oferecem, preferencialmente, cursos de formação e capacitação na área de enfermagem, por falta de espaços adequados para a prática de outros cursos, e seus alunos assistem às aulas teóricas na escola, ou em unidades descentralizadas, e fazem as aulas práticas nas unidades assistenciais, atuando diretamente nos serviços de prestação de assistência. 
Com base nas discussões de programa arquitetônico vis-à-vis programa pedagógico esta dinâmica se modificará, tanto pela introdução de vários outros cursos de formação e capacitação, tais como biodiagnóstico, farmácia, nutrição, vigilância sanitária e epidemiológica, odontologia e radiologia, como pela modificação das rotinas de inserção dos alunos nas atividades práticas.

Espera-se que com a criação dos laboratórios de práticas nas novas escolas possa-se introduzir uma etapa intermediária entre as aulas teóricas e a prática em serviços, em espaços específicos concebidos à semelhança dos reais, inclusive com todo o mobiliário, os equipamentos e as instalações existentes nas unidades de saúde da Rede SUS.

Dessa forma, propõem-se que os primeiros contatos dos alunos com os procedimentos e as tecnologias da atenção à saúde, do ponto de vista dos cuidados primários ou terciários, se dêem em ambientes simulados, ou cenários, onde as turmas ganharão intimidade com a operacionalização de instrumental e equipamentos, evitando-se, com isso, um possível desconforto aos pacientes no momento dos procedimentos práticos nos serviços da Rede SUS.

Outro ganho advindo da introdução dessa etapa intermediária na formação e capacitação desses profissionais é a possibilidade de se evitar um grande número de estragos no instrumental médico-cirúrgico e nos equipamentos biomédicos, alguns caros e sofisticados, pela inabilidade dos operadores no uso cotidiano e nas rotinas de limpeza dos mesmos.

\section{Os primeiros passos}

Criado em final de setembro de 2001, com o objetivo de apoiar as ETSUS em suas propostas de reestruturação físico-funcional-pedagógica, o Escritório de Projetos e Obras do Projeto de Profissionalização dos Trabalhadores da Área de Enfermagem (PROFAE) iniciou seus trabalhos tendo, como laboratório, a ETSUS de Natal (RN) e, como diretrizes, as discussões com as equipes técnicas do PROFAE.

O objetivo inicial da equipe de arquitetos foi desenvolver um programa arquitetônico básico para as ETSUS, que:

- Contemplasse as principais atividades pedagógicas preconizadas no novo modelo de formação para técnicos e auxiliares na área da saúde recomendados pelo PROFAE/MS, envolvendo aulas presenciais e a distância, videoconferências e recursos da internet.

- Reproduzisse, nas escolas, alguns ambientes assistenciais, principalmente os hospitalares, considerados relevantes, de modo a propiciar uma estreita semelhança entre as duas edificações - o hospital e a escola - facilitando a aproximação do aluno, em seu espaço pedagógico, com a realidade dos espaços e ambientes onde ocorrem os diferentes processos de trabalho em saúde relativos às categorias profissionais em questão. 
- Dessem conta de absorver o aporte de tecnologia imposto à atenção à saúde nos últimos anos, e implementados na Rede SUS pelo Ministério da Saúde, através de programas e projetos de investimentos tais como: Projeto Reforsus, Rede Nacional de Informações em Saúde, Programa de Saúde da Família, Gestação de Alto Risco, Política Nacional de Alimentação e Nutrição, entre outros.

A metodologia proposta, na etapa inicial dos trabalhos, consistiu na identificação das habilitações a serem agregadas nas ETSUS, consoantes com os investimentos que haviam sido considerados prioritários para os investimentos do projeto REFORSUS, para as quais foram propostos layouts apresentados inicialmente para a equipe do PROFAE e, posteriormente, discutidos e reformulados numa oficina com o CEFOPE de Natal (RN).

Os estudos preliminares para a reforma e ampliação do CEFOPE de Natal foram concebidos a partir de três diretrizes de naturezas distintas, mas de igual relevância, são elas:

- A construção de uma identidade para as ETSUS; pela introdução de elementos arquitetônicos, em destaque, tais como escadas, castelos d'água, volumes específicos, que combinem a cor vermelha, identificando a saúde, e a azul, simbolizando o SUS.

- A concepção de projetos que privilegiassem as soluções racionalizadoras do ponto de vista do uso de energia elétrica, tais como uso de elevadores hidráulicos para acesso aos pavimentos superiores e iluminação e ventilação naturais.

- A concepção de espaços flexíveis, adaptáveis às futuras inovações das áreas de educação e saúde.

Nesta etapa, nasceram os primeiros laboratórios de práticas, resultando da observação dos processos de trabalhos intrínsecos às principais atividades dos diferentes ambientes em cada um dos laboratórios de práticas. Dessa forma, organizaram-se espaços pedagógicos distintos, através de layout, identificando as necessidades de mobiliário, equipamentos e instalações (Ibam, 1996), além de informar a capacidade máxima de ocupação de cada ambiente, pela identificação do número ótimo de alunos para cada procedimento a ser praticado, conforme exemplos a seguir:

1) Laboratório de práticas em análises clínicas, envolvendo as categorias profissionais de auxiliar de enfermagem e técnicos de bioquímica e citologia. A estrutura do espaço interno deste laboratório permite a realização de aulas teóricas no próprio laboratório (Figura 1).

2) Laboratório de práticas de enfermagem, para os cursos de formação e capacitação de auxiliares e técnicos de enfermagem (Figura 2). 


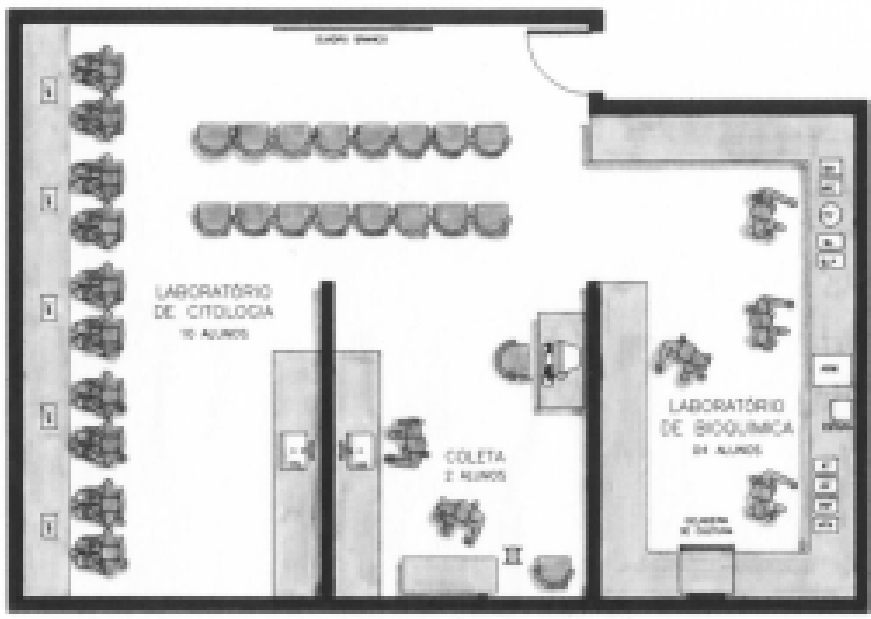

Figura 1 -

Laboratório

de práticas em

biodiagnóstico.

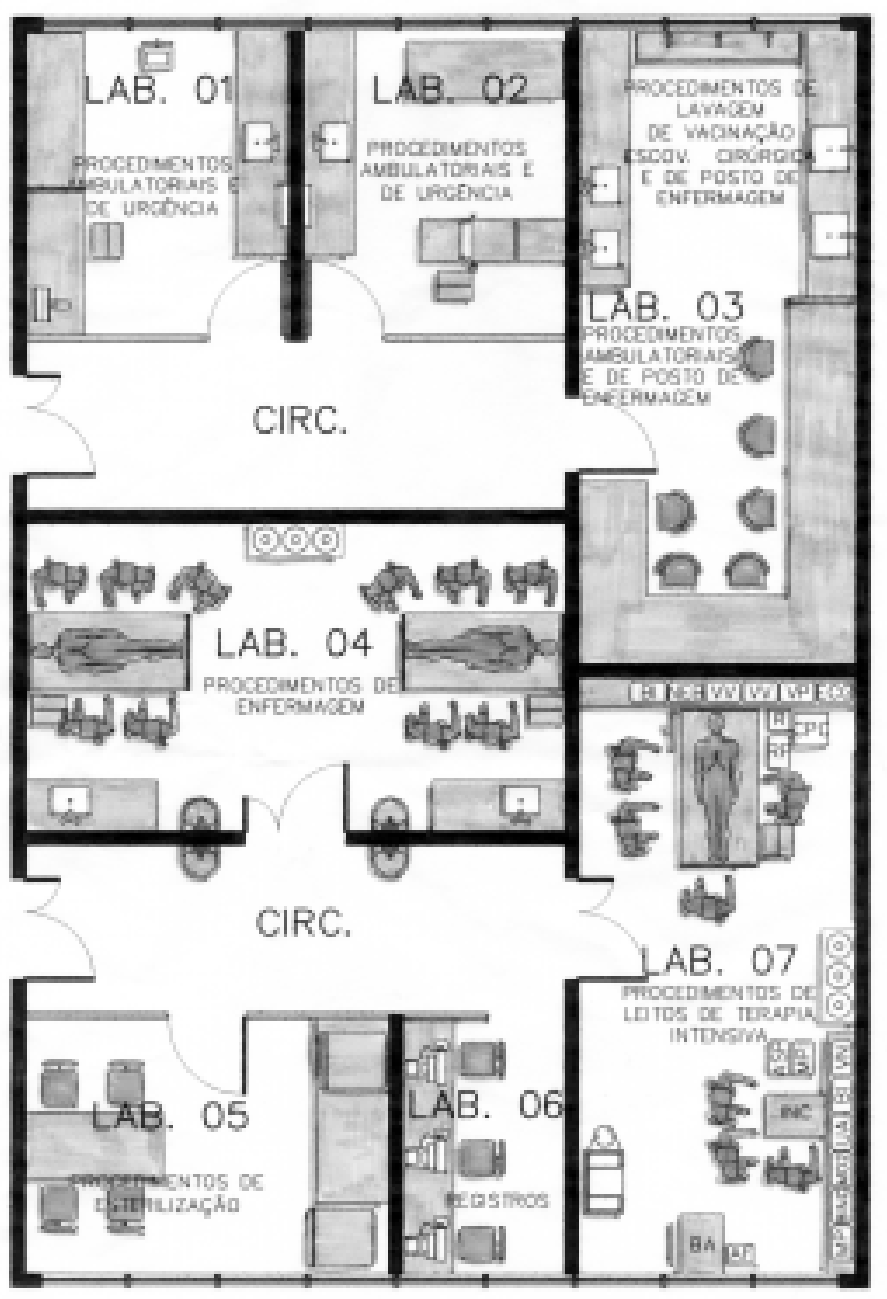

Figura 2 -

Laboratório de

práticas de

enfermagem. 
Além dos laboratórios de práticas, das salas de aula e áreas administrativas, cada ETSUS contará com uma biblioteca com capacidade de, no mínimo, seis mil volumes, com acesso à internet e à Biblioteca Virtual em Saúde/ BVS, BIREME/OMS, além de um auditório, ou sala de multimeios, com capacidade para, no mínimo, oitenta pessoas. Esses dois ambientes pedagógicos complementares serão abertos ao público e servirão para integrar a ETSUS à comunidade.

Dessa forma, o programa arquitetônico básico para as ETSUS, em consonância com a proposta pedagógica preconizada pelo PROFAE, previu os seguintes ambientes:

Laboratórios de práticas

Laboratório de informática para vinte alunos;

Laboratório de atividades de enfermagem, com as seguintes atividades:

- leitos comuns - adulto, infantil e neonato;

- leitos intensivos - adulto, infantil e neonato;

- de ambulatório, urgência e emergência;

- de atendimento domiciliar e bome care;

- de posto de enfermagem, escovação cirúrgica, anotações em prontuários e de vacinação.

Laboratório de esterilização;

Laboratório de nutrição;

Laboratório de odontologia;

Laboratório de bioquímica, citologia e coleta;

Laboratório de farmácia;

Laboratório de registros em saúde;

Laboratório de lactário, banco de leite e cozinha dietética.

Salas de aula

Em número compatível com o porte da ETSUS

Espaços Pedagógicos Complementares

Biblioteca;

Auditório;

Sala de multimeios, reversível para auditório.

Áreas administrativas

Compatível com a estrutura organizacional da escola.

\section{Um susto: ETSUS em larga escala}

Entretanto, em fevereiro de 2002, o trabalho experimental que vinha sendo elaborado pelo escritório de projetos e obras do PROFAE ganhou uma dimensão inesperada, quando surgiu a possibilidade de celebração de 14 convênios entre o Ministério da Educação, o Ministério da Saúde e as secretarias estaduais de Saúde, com o objetivo de modernizar as 
escolas existentes e conceber novas, totalizando a necessidade de intervenção física em 14 ETSUS, constituindo-se em um grande desafio para a equipe de arquitetos.

O clima no escritório de projetos era de dúvidas e expectativas: Nossa idéia inicial, recém-concebida, daria conta de todas as escolas? Como elaborar 14 layouts, com um padrão de qualidade aceitável, em pouco tempo?

A solução encontrada pela equipe foi a concepção de uma metodologia para elaboração dos projetos que abrangesse tanto as novas construções como as reformas, e que possibilitasse a padronização de espaços pedagógicos e não de espaços físicos, de modo a garantir o respeito às diversidades de cada escola, quanto ao porte, à complexidade, ao tipo de terreno disponível e, sobretudo, às condições específicas de conforto e segurança das edificações, impostas pelas características regionais de cada estado.

Dessa forma, os espaços pedagógicos se conformaram por meio da articulação entre os diferentes processos de trabalho das categorias profissionais em questão, e se transformaram em blocos articulados e flexíveis, adaptáveis às diferentes formas físicas de cada escola.

Por outro lado, identificou-se a necessidade e a possibilidade de se conceber uma estrutura física padronizável para escolas com semelhanças de programa pedagógico, com características regionais aproximadas e terrenos planos, surgindo o BASICÃO, com módulos articuláveis entre si (Figura 3).
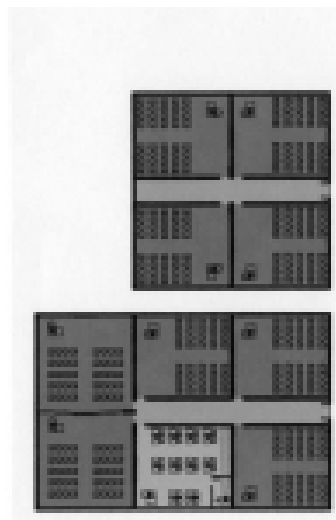

SALAS DE AULA
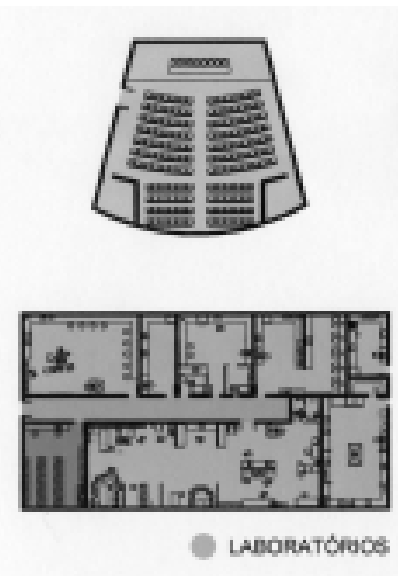
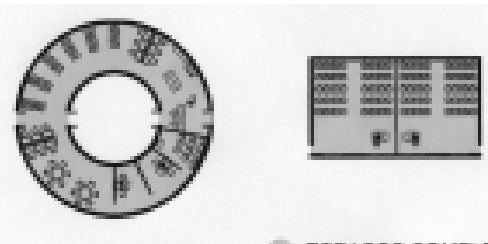

ESPACOS COMPLEMENTARES

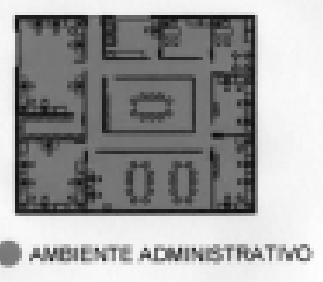

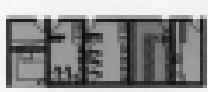

OEMWS ARERS

Figura 3 - Módulos articuláveis.

E como numa grande sala de recreação, os arquitetos passaram a "brincar de Lego", concebendo espaços físicos diferentes, mas com as mesmas características enquanto espaços pedagógicos: em curva, como a de Natal (RN), longilíneas como as de Porto Velho (RO) e Belém (PA), compactas, como as de Porto Alegre (RS) e Belo Horizonte (MG), e esparramadas, como as de Manaus (AM), Palmas (TO) e Curitiba(PR). 


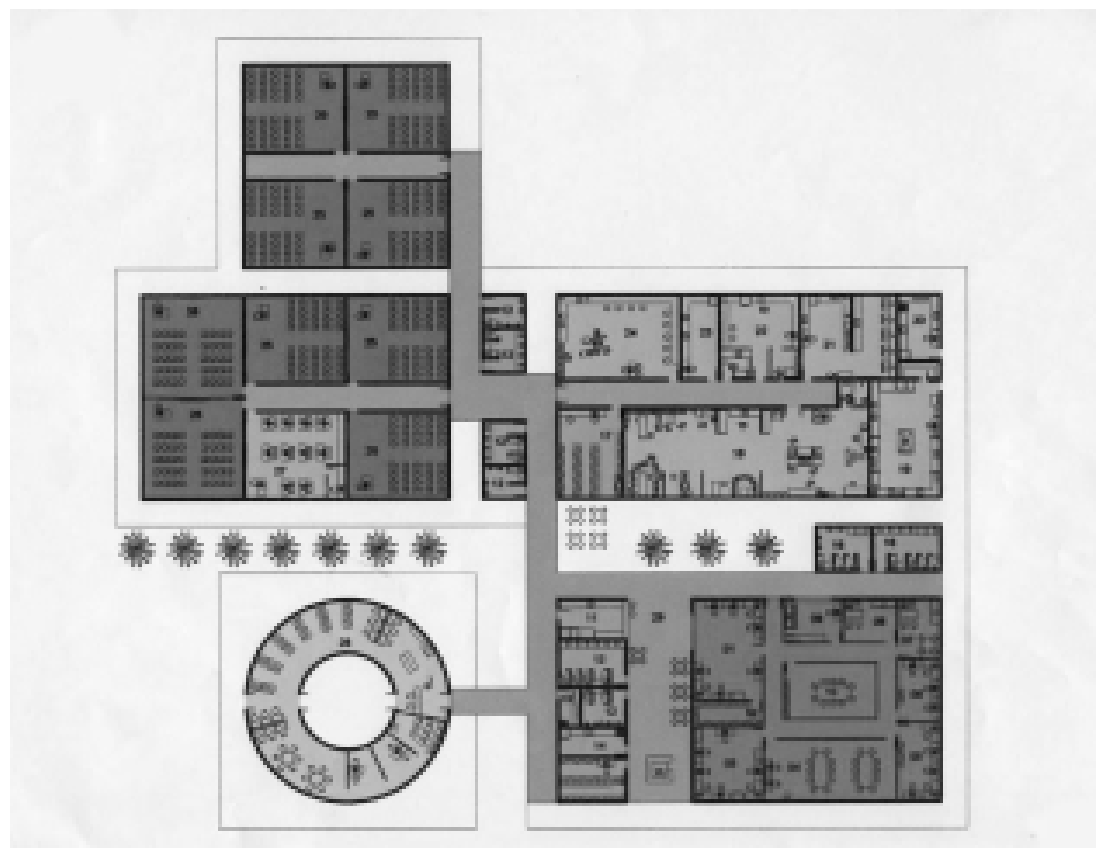

Figura 4 - ETSUS de Manaus (AM).

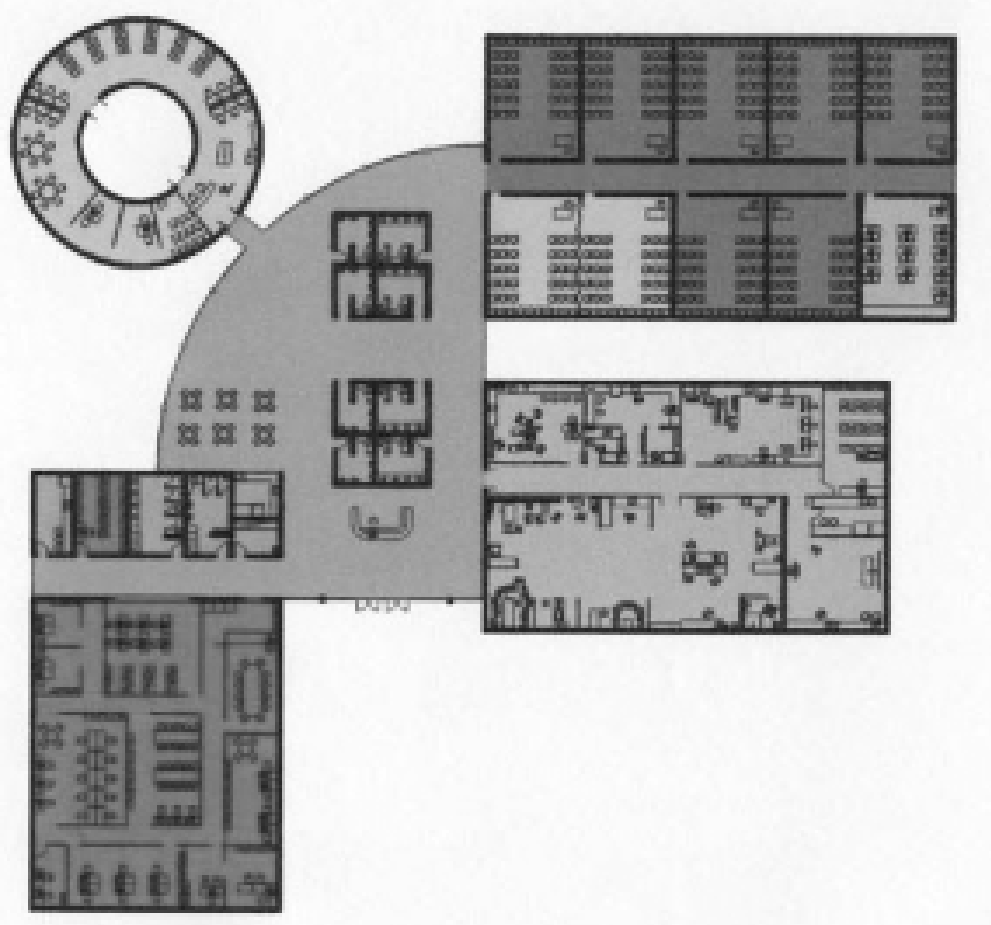

Figura 5 - ETSUS de Curitiba (PR). 


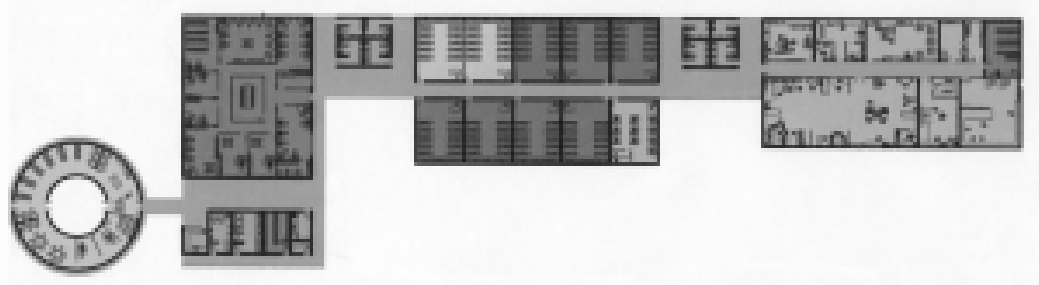

Figura 6 - ETSUS de Belém (PA).
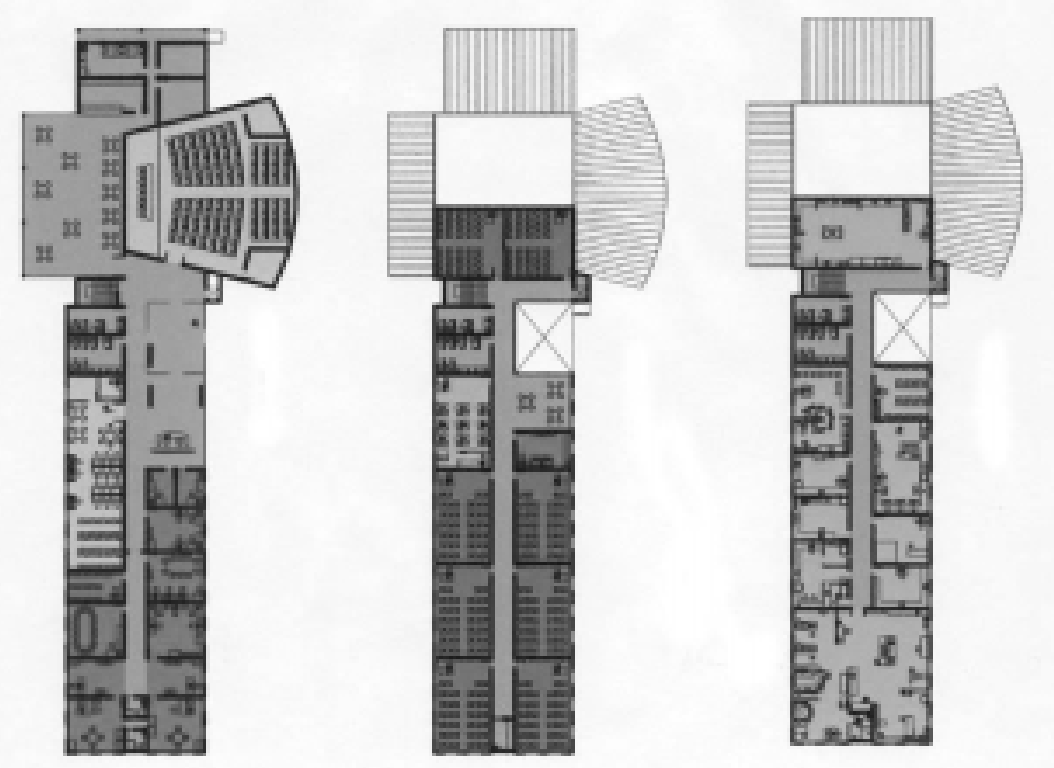

Figura 7 - ETSUS de Porto Velho (RO).

Dentro da metodologia proposta, coube ao escritório de projetos e obras do PROFAE elaborar os estudos preliminares dos projetos, com definição dos partidos, das implantações nos terreno, dos layouts e dos estudos de fachada.

Paralelamente a esses estudos preliminares, e com o objetivo de contratar na iniciativa privada o desenvolvimento dos projetos executivos, foram padronizados instrumentos para contratação e supervisão dos serviços a serem terceirizados, com vistas a se obter o material técnico necessário à execução das obras.

Dessa forma, em agosto de 2002, foi possível apresentar às equipes de 17 Escolas Técnicas de Saúde do SUS os projetos executivos de construção e reforma, com a expectativa de que as obras tenham início em 2003.

A seguir, destacamos algumas das ETSUS concebidas, com o objetivo de ilustrar a diversidade de projetos surgidos a partir da concepção básica adotada pelo escritório de projetos e obras do PROFAE. 


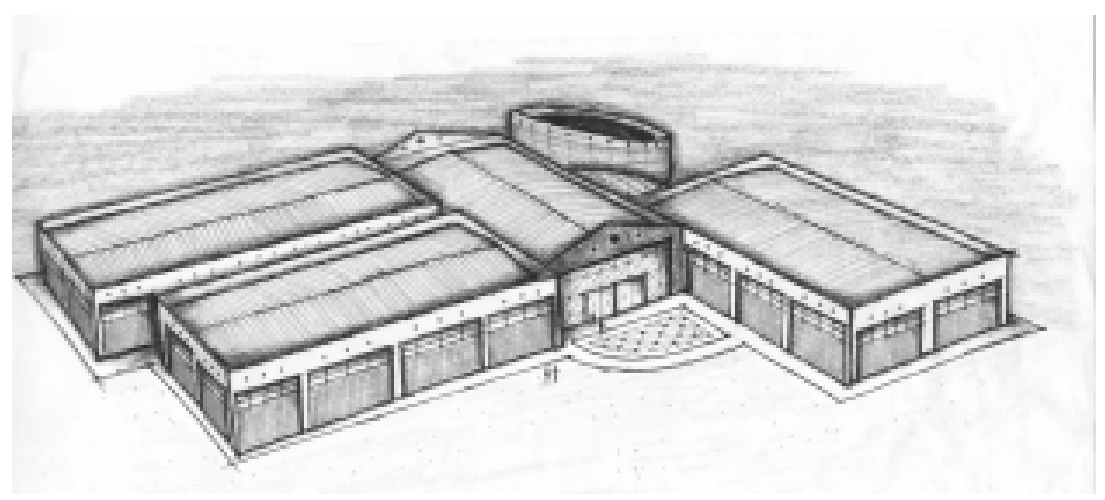

Figura 8 - ETSUS Curitiba (PR).

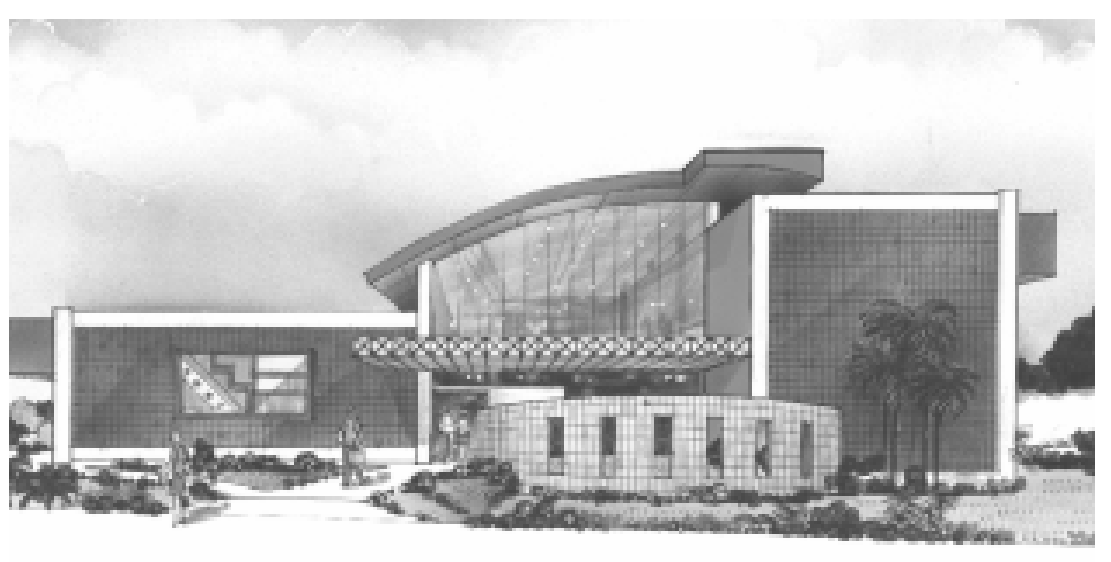

Figura 9 - ETSUS de Campo Grande (MS).

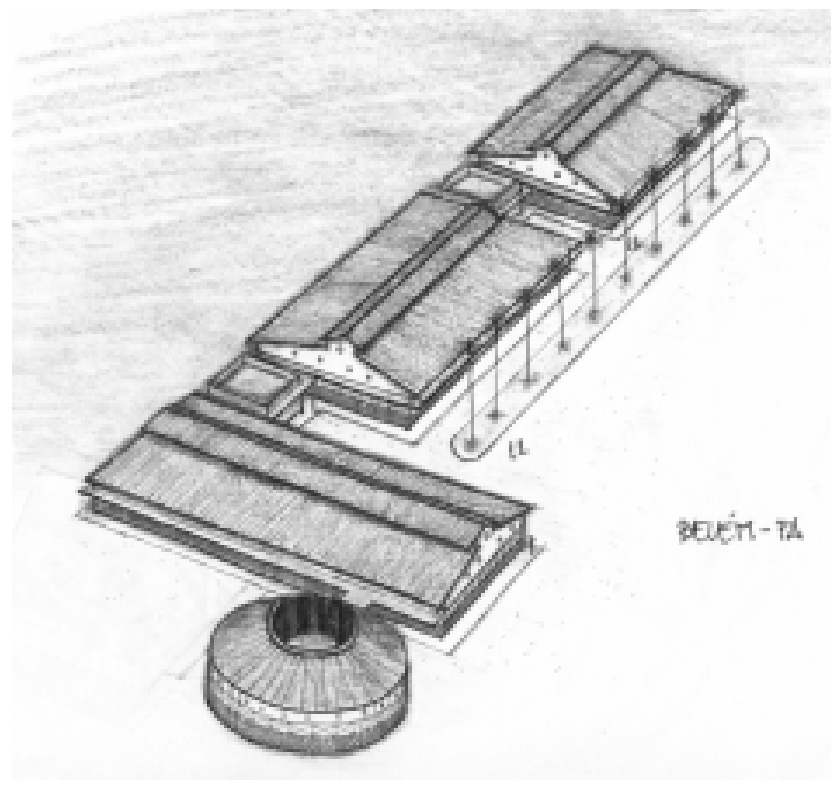

Figura $10-$

ETSUS de Belém

(PA). 


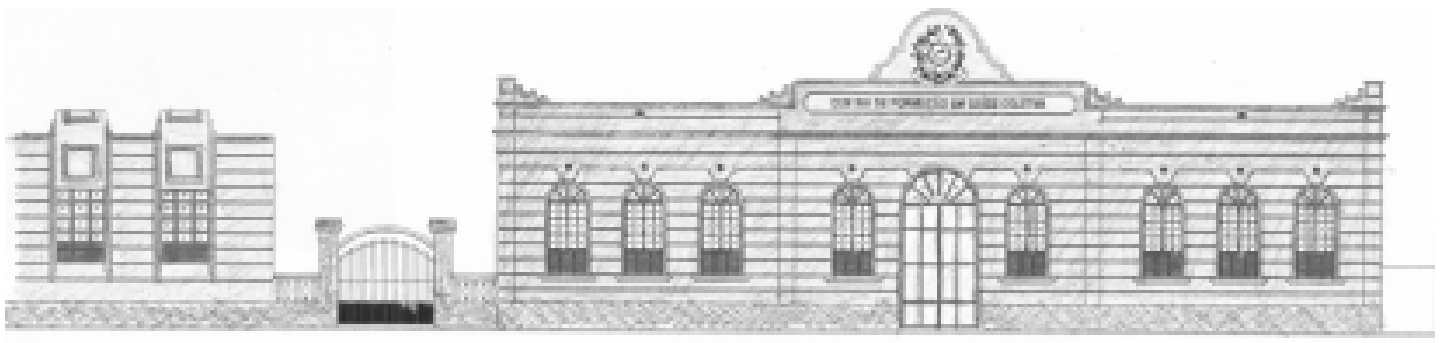

Figura 11 - ETSUS de Vitória (ES).

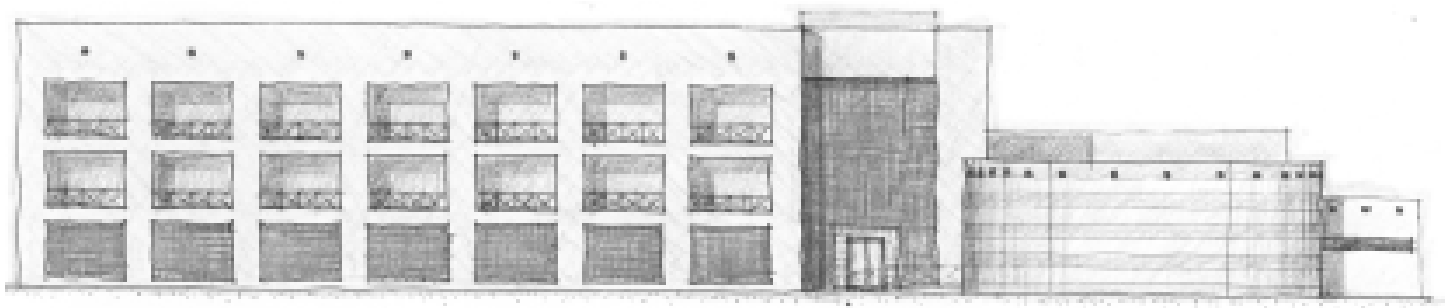

Figura 12 - ETSUS de Porto Velho (RO).

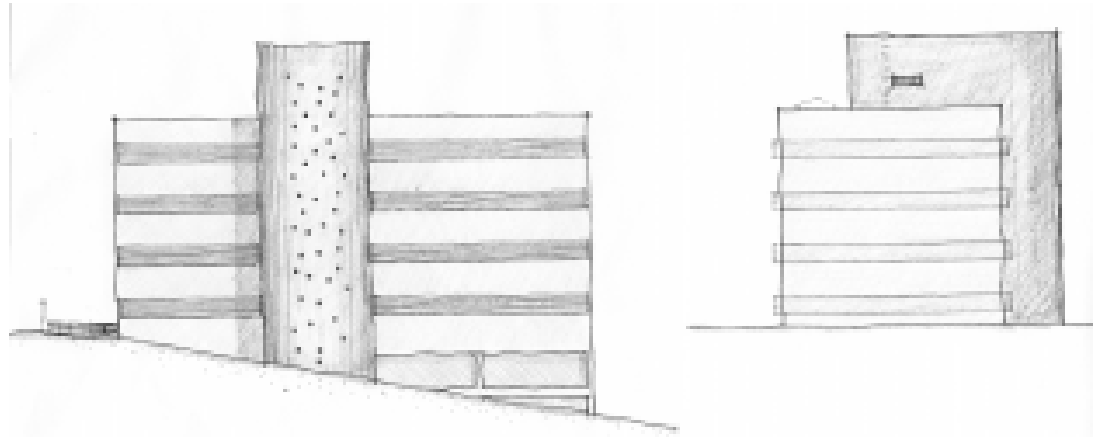

Figura 13 - ETSUS de Belo Horizonte (MG).

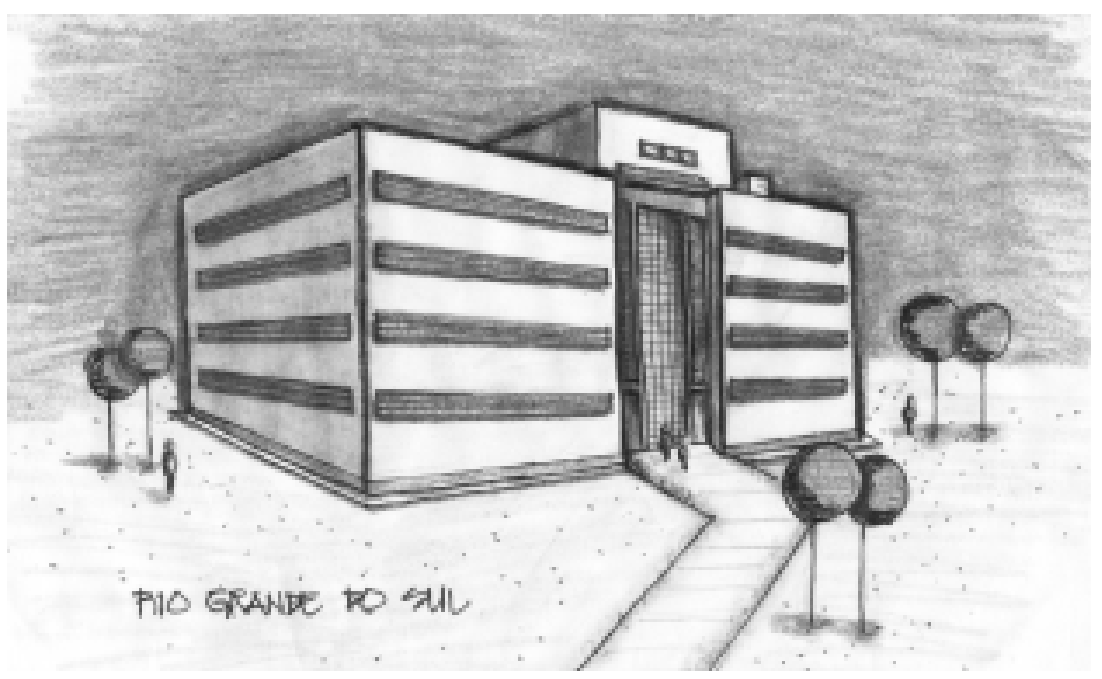

Figura 14 - ETSUS de Porto Alegre (RS). 
Merece destaque a proposta do escritório de projetos e obras do PROFAE para a ETSUS do Rio de Janeiro, Enfermeira Izabel dos Santos, que buscou romper com o atual formato da escola, ao alterar sua entrada principal e estruturar os espaços pedagógicos complementares, biblioteca e auditório, em uma edificação anexa ao prédio principal, de fácil acesso pelo público externo, como uma forma de incentivar a utilização dos mesmos como espaços comunitários destinados a atividades de saúde.

\section{Perspectivas para o desenvolvimento dos trabalhos}

Espera-se que as obras de construção, reforma e ampliação se desenvolvam durante os anos de 2003 e 2004.

Paralelamente, consoante com as diretrizes do Ministério da Saúde e do Ministério da Educação quanto à necessidade de avaliar os resultados dos projetos de investimentos na melhoria da assistência à população, durante a execução das obras serão desenvolvidos e testados os protocolos e as dinâmicas de aula pelas equipes das ETSUS, das SES envolvidas, do PROFAE e de unidades hospitalares de referência em cada estado.

A partir desses instrumentos, e baseados nas metas de produção pactuados no momento da aprovação dos convênios com cada ETSUS, serão identificados indicadores quantitativos e qualitativos, como, por exemplo, número de acidentes com pacientes envolvendo o uso de tecnologia em UTI neonatal — que serão medidos antes e depois da inserção dos egressos dos cursos ministrados pelas novas ETSUS, que poderão aferir os resultados na clientela assistida, fruto da nova dinâmica pedagógica implantada pelos convênios PROEP/MEC e PROFAE/MS.

\footnotetext{
Agradecimentos

À equipe de arquitetos do escritório de projetos e obras, Alexandre Martha e Georgiana Goulart, e, em especial, à Mônica Salgado pelo desprendimento na coordenação dos trabalhos;

Às escolas técnicas visitadas, pelo carinho com que acolheram os arquitetos;

Aos engenheiros do PROEP/MEC, Rubens Laurini e Antônio Marcos Pereira, pelo espírito de equipe e pela parceria;

A Valcler Rangel, Ena Galvão e Márcio Arruda e demais profissionais do Componente II do PROFAE;

À Magda, da ETSUS de Natal, e à Ana Maria e Diana, da ETSUS FHEMIG/BH/MG, pelas críticas e sugestões;

Aos escritórios de arquitetura contratados, pelo trabalho desenvolvido;

À Rita Sório, gerente geral do PROFAE, pela oportunidade de orientar a equipe de arquitetos na concepção de uma nova escola técnica de Saúde do SUS.
} 
LUISA REGINA PESSOA

\section{REFERÊNCIAS BIBLIOGRÁFICAS}

Brasil. Ministério Revista Mais Saúde, ano II, no 6 .

da Saúde

2002

Castro, Janete Lima de;

Izabel dos Santos: a arte e a paixão de aprender fazendo.

Santana, José Paranaguá

Natal, Observatório RH NESC/UFRN.

de e Nogueira,

Roberto Passos

2002

IBAM

1966

Manual para elaboração de projetos de edifícios de saúde na cidade do Rio de Janeiro: posto de saúde; centro de saúde e unidade mista. Rio de Janeiro, IBAM/CPU, PCRJ/SMU, 120p.

Sório, Rita Elisabeth da Rocha

'Inovações no campo da gestão de projetos sociais: uma reflexão à luz da experiência do PROFAE'. Em PROFAE educação profissional em saúde e cidadania. Brasília, Editora MS, pp.17-29. 